
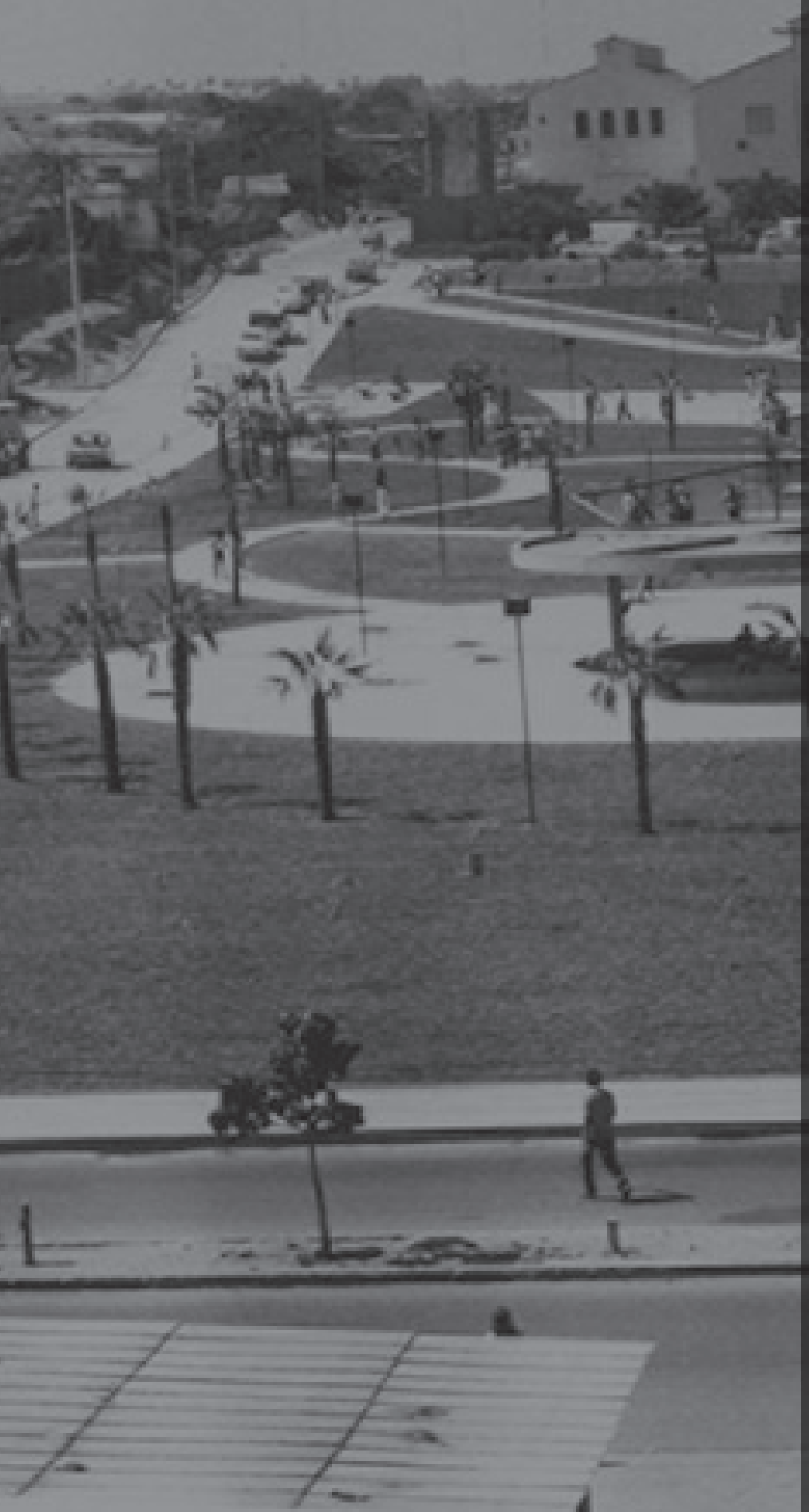

1. O artigo é resultado do projeto apoiado pelo Edital Universal CNPq, "A presença de Roberto Burle Marx no Nordeste: sua obra e a importância para o patrimônio cultural da cidade de Teresina, Piauí".

2. Doutora em Engenharia Agrícola (Unicamp), mestra em Arquitetura (EESC/USP), especialista em Urbanismo (UFMG), arquiteta (UFPE), professora associada do Departamento de Construção Civil e Arquitetura e do Mestrado e Doutorado em Desenvolvimento e Meio Ambiente da Universidade Federal do Piauí (UFPI). E-mail: izalopes@uol.com.br.

3. Doutoranda em Arquitetura e Urbanismo (UFSC), mestra em Urbanismo pela Universitat Politecnica da Catalunya-UPC, Barcelona, Espanha, mestra em Arquitetura e Urbanismo (UFRN), especialista em Meio Ambiente (UFPI), arquiteta e urbanista (UFPE), professora do Departamento de Construção Civil e Arquitetura da UFPI. E-mail: kareninamatos@yahoo.com.br.

4. Doutoranda em Desenvolvimento e Meio Ambiente (UFPI), mestra em Arquitetura (EESC/USP), arquiteta (Universidade Mackenzie), professora do Departamento de Construção Civil e Arquitetura da UFPI. E-mail: re.mattaraia@ufpi.edu.br.

5. Mestre em Planejamento Urbano (UFSC), professor da Uninovafapi, arquiteto e urbanista (UFPI). E-mail: josehamilton.arq@gmail.com.

6. Doutoranda em Desenvolvimento e Meio Ambiente (UFPI), mestra em Engenharia Civil (UFC), arquiteta e urbanista (UFPI), funcionária da Divisão de Projetos da Prefeitura Universitária (UFPI). E-mail: geovanarvieira@gmail.com.

7. Arquiteta e urbanista (UFPI), professora do Departamento de Construção Civil da UFPI. E-mail: nayanearquitetura@ gmail.com.

\section{DOI: 10.5752/P.23161752.2014v21n29p62}




\title{
A PRESENÇA DE ROBERTO BURLE MARX NA CIDADE DE TERESINA, PIAUI'
}

\author{
THE PRESENCE OF ROBERTO BURLE MARX INTERESINA, PIAUÍ
}

LA PRESENCIA DE ROBERTO BURLE MARX EM LA CIUDAD DE TERESINA, PIAUI

\author{
Wilza Gomes Reis Lopes ${ }^{2}$ \\ Karenina Cardoso Matos $^{3}$ \\ Regina Ângela Mattaraia ${ }^{4}$ \\ José Hamilton Lopes Leal Junior ${ }^{5}$ \\ Geovana Alves Rocha Vieira ${ }^{6}$ \\ Nayane Áurea Santiago Costa ${ }^{7}$
}

\section{Resumo}

Os jardins urbanos representam uma forma de se reencontrar com o meio natural, sendo áreas importantes para o equilíbrio ambiental das cidades. Roberto Burle Marx é um dos mais representativos paisagistas brasileiros, de renome internacional. Seus projetos, ligados às ideias nacionalistas dos arquitetos modernos, mudaram o conceito do paisagismo brasileiro, com a introdução de espécies autóctones no jardim brasileiro. Neste estudo, são descritos e analisados os três projetos de jardim de Burle Marx existentes na cidade de Teresina, Piauí, destacando sua importância cultural para a cidade.

Palavras-chave: Espaços livres. Jardim histórico. Preservação. Patrimônio cultural.

\begin{abstract}
The urban garden is one form to reconnect with the natural environment, because the garden is an important area for the environmental balance of cities. Roberto Burle Marx is one of the landscaper most representative of the Brazil of international renown. Their projects linked to nationalist ideas of the modern architects have changed the concept of the Brazilian landscape with the introduction of native species in the Brazilian Garden. In this study are described and analyzed the three garden projects Burle Marx, existing in the city of Teresina, Piauí, highlighting its cultural importance to the city.
\end{abstract}

Keywords: Open spaces. Historic garden. Preservation. Cultural heritage.

\begin{abstract}
Resumen
Los jardines urbanos son una manera de volver a conectar con el entorno natural son, como areas importantes para el equilibrio ambiental de las ciudades. Roberto Burle Marx es uno de los paisajistas más representativos de Brasil, reconocido internacionalmente. Sus proyectos, vinculados a las ideas nacionalistas de los arquitectos modernos, cambiaron el concepto del paisaje brasileño con la introducción de especies exóticas en el jardín brasileño. En este estudio se describen y analizan los tres proyectos de jardines de Burle Marx, que existe en la ciudad de Teresina, Piauí, destacando su importancia cultural para la ciudad.
\end{abstract}

Palabras clave: Espacios abiertos. Jardín histórico. Preservación. Patrimonio cultural. 


\section{Introdução}

Desde os primórdios, o ser humano manteve uma relação íntima com a natureza, que Ihe servia de alimento e abrigo. Essa relação, no entanto, tornou-se cada vez menos intensa no decorrer da história, quando surgiram as primeiras cidades e a posterior expansão destas, passando pela Revolução Industrial até a atualidade. Hoje, o homem busca formas de se reencontrar com o meio natural, seja em passeios ao campo ou à praia, praticando esportes ao ar livre ou cultivando espaços verdes em meio ao concreto dos ambientes construídos.

O paisagismo entra em cena como uma forma racional de elaborar esse novo contato homem-natureza por meio dos espaços verdes ou jardins. Os primeiros jardins surgiram em áreas privadas como templos e palácios, como no Palácio de Alhambra, na Espanha (1492), ou no Taj Mahal, na Índia (1632) (SÁ CARNEIRO; SILVA; GIRÃO, 2003). Os jardins sempre tiveram papel importante na história da Arquitetura e, por extensão, na história da humanidade. Representam uma tentativa de retorno à natureza, pelo qual o homem tende a voltar às suas origens naturais.

O jardim traz à tona a necessidade humana de harmonia, de contato com o meio natural, de escapar do tumultuado mundo urbano. Em qualquer religião ou cultura, encontramos exemplos do relacionamento entre o homem e a natureza, e a importância desta no bem-estar físico-emocional do homem. Vieira (2007, p. 55) ressalta essa ideia, afirmando que "cada esforço de resgate do jardim volta a ser uma lembrança de um viver junto à natureza, fonte de prazer, lazer e reflexão".

Locais livres de construção, de acordo com Serpa (1997), são necessários no cenário urbano por manterem o equilíbrio ambiental nas cidades, servindo de ferramenta para a qualificação e recuperação de espaços degradados.

Os espaços livres têm grande responsabilidade na formação da identidade cultural das cidades, configurando-se também como importantes elementos para a melhoria ambiental e como locais referenciais de lazer para a população. Tais áreas caracterizam a paisagem urbana, pois são espaços que criam valores referenciais para seus habitantes. Um dos aspectos fundamentais para a qualidade de vida dos citadinos seria a criação de referenciais urbanos, por meio da caracterização fisionômica dos espaços urbanos (BARTALINI, 1995).

Reconhecido como o mais importante paisagista brasileiro, Roberto Burle Marx "desenvolveu projetos em vários países e em diversas cidades brasileiras, nos quais sempre estava presente sua preocupação com a harmonia, prazer estético e integração ecossistêmica da paisagem" (LOPES et al., 2007, p. 2). Uma das características mais marcantes em seus projetos era o uso extensivo da vegetação brasileira, enfocando, também, o conhecimento das espécies nativas da região em que seria inserido cada jardim.

Devido à importância de sua obra, faz-se necessária a realização de estudos para garantir a permanência, a divulgação e a valorização de seus jardins. Pesquisas têm sido desenvolvidas 
bem como já foram vários os livros publicados sobre a vida e a obra do paisagista, tanto no Brasil como em outros países. Mas geralmente são estudadas as suas obras mais importantes, e nem todas as cidades são contempladas.

Em Teresina, são encontrados três exemplos de projetos de Roberto Burle Marx: os jardins do Palácio do Karnak (sede do governo estadual), exemplo de espaço semipúblico; os jardins do Rio Poti Hotel, espaço privado; e a Praça Monumento Da Costa e Silva, exemplo de espaço público. Neste trabalho, é apresentada a descrição dos projetos de Burle Marx encontrados na cidade de Teresina.

\section{Patrimônio cultural e jardim histórico}

É importante a preservação de referenciais históricos nos espaços urbanos para que, assim, se possa transmitir às gerações futuras o conhecimento de aspectos relacionados a sua identidade e seus significados, porém se deve saber o que, de fato, deve ser preservado.

A paisagem urbana como resultado das ações do homem, um relato sólido de épocas e acontecimentos que pode sanar a necessidade de memória do indivíduo, tornando-o novamente parte do todo, contribuindo, assim, tanto para a formação de vínculos sociais quanto para a afirmação de uma cultura ou comunidade. Segundo Carneiro (2006, p. 19), “O patrimônio mundial material atua como um estímulo para a nossa memória e cristaliza em suas manifestações a especificidade de uma cultura, assim como sua vocação universal".

Para Nunes (2005, p. 233), a cidade é "memória organizada, natureza e cultura. Tem história, personagem e uma trama de desejos individuais e de projetos." Com isso, a preservação da paisagem cultural se faz de grande importância, visto que, por meio dela, há a preservação do ambiente histórico e patrimonial de uma cidade.

Toda paisagem se torna parte de uma história, portanto faz parte do patrimônio cultural de uma cidade, não que tudo deva ser preservado, mas acompanhando a linha preservacionista moderna de raciocínio que, segundo Lima (2002), não elege apenas o monumental, mas o significativo. Bosi (1994 citado por LEITÃO, 2002) ressalta a importância da identidade simbólica causada por ambientes urbanos para a população. A função social da memória é responsável por, simbolicamente, proporcionar às pessoas o resgate do tempo que correu, contribuindo para a preservação do lugar, devido ao valor histórico e afetivo que representa para a cidade e para sua população.

Para uma possível associação simbólica, Carneiro (2006) cita a necessidade de uma consciência dos acontecimentos históricos, no entanto é a ausência dessa consciência que, muitas vezes, dificulta a preservação, pois, como afirma Martins (2006), o patrimônio nem sempre é fruto da coletividade, sendo, muitas vezes, produto de contextos econômicos, políticos e sociais tendo origem em decisões de grupos, o que o torna passível de questionamento e múltiplas interpretações. 
No âmbito da preservação do espaço como patrimônio cultural, destaca-se a reflexão sobre seu valor histórico, ou seja, pensá-lo como fator de memória e identidade de um povo. Assim, além de seu caráter científico e funcional, estético e cultural, ele também deve ser avaliado como elemento importante para a sociedade civil no tocante à preservação de seu valor no sentido físico, político e econômico (FRONER, 2002). Segundo Pelegrini (2006, p. 116), na memória "residem aspectos que a população de uma dada localidade reconhece como elementos próprios da sua história, da tipologia do espaço onde vive, das paisagens naturais ou construídas".

Nesse sentido, Murta e Goodey (2002, p. 19) ressaltam que "o processo de interpretação baseado na comunidade responde, pois, à necessidade de o planejamento municipal proteger e desenvolver um sentimento de lugar, de transmitir seus valores, sua ecologia e sua história às novas gerações".

Os jardins fazem parte do patrimônio cultural das cidades, podendo ser reconhecidos como jardim histórico. Em 1981, o Comitê Internacional de Jardins Históricos e o International Comittee on Monuments and Sites / International Federation of Landscape Architects - Icomos/IFLA elaboraram documento para proteção de jardins históricos, denominado "Carta de Florença" (DELPHIN, 2005). Na "Carta de Florença", em seu artigo $1^{\circ}$, jardim histórico é definido como "uma composição arquitetônica e vegetal que, do ponto de vista da história ou da arte, apresenta um interesse público. Como tal, é considerado monumento" (CURY, 2000, p. 253).

Na visão de Sá Carneiro (2009a, p. 212), “Jardins históricos são gestos humanos marcantes de um tempo sobre a paisagem cultural." Segundo Andrade e Martins (2004), todo jardim histórico é um bem cultural que, com o decorrer do tempo, vai adquirindo valores estéticos, culturais, sociais e históricos de cada sociedade, sendo considerado um monumento vivo. Destaca-se, ainda, que a "expressão jardim histórico é igualmente aplicável a pequenos jardins ou a grandes parques, quer sejam formais ou paisagens" (ICOMOS, 1982, p. 2).

Costa e Monteiro (2002, p. 291) ressaltam que "nossas paisagens urbanas são reveladoras das inter-relações entre intenções humanas e os processos naturais. Elas são, portanto, paisagens culturais, que são constantemente reestruturadas em função dos valores que Ihes atribuímos".

\section{O paisagista Roberto Burle Marx}

Burle Marx é tido como um dos mais conhecidos paisagistas no cenário nacional e internacional. Nasceu em 4 de agosto de 1909, em São Paulo, filho de pai alemão e mãe pernambucana, mas foi criado no Rio de Janeiro e, desde criança, já se interessava pela jardinagem. Foi em visita à estufa do Jardim Botânico de Dahlem, durante uma viagem a Berlim, no período entre 1928 a 1929, que ele descobriu a flora brasileira (FLEMING, 1996). Foi nesse local que o paisagista, segundo Frota (2009, p. 138), "se verá diante das plantas brasileiras que, a partir de então, impelirão rumo tão peculiar ao seu percurso de artista como paisagista". 
Nas estufas de Dahlem, Burle Marx deslumbrou-se com palmeiras, filondredos, marantas, caládios e cactos. Dessa forma, segundo Fleming (1996, p. 30), Burle Marx, "remoendo sobre as diferenças entre os cactos espinhados, as folhas grandes e brilhantes e a delicadeza das plantas que floriam do lado de fora, começou a se dar conta de que era essencial elaborar um vocabulário personalizado caso quisesse levar jardinagem a sério".

Estudioso da flora brasileira, Burle Marx costumava realizar expedições pelo interior do Brasil, com o objetivo de conhecer a flora brasileira, coletando espécies que eram plantadas em sua casa, no sítio Santo Antônio da Bica, na baixada de Guaratiba, Rio de Janeiro. Para Motta (1983, p. 10), “O sítio Santo Antônio da Bica é sua casa, é laboratório onde realiza cruzamentos de plantas e obtém variedades novas". Burle Marx consolidou a identidade paisagística brasileira com o uso de vegetação local, análise do clima do entorno de suas obras e por aliar seus conhecimentos em artes plásticas à produção dos desenhos de pisos e composições vegetais.

O século XX, segundo Macedo (1999), foi marcado pela consolidação da arquitetura paisagística brasileira, que se libera das antigas influências europeias e, sob forte influência nacionalista, assume uma identidade própria. Nesse período, destacam-se os projetos de Roberto Burle Marx, que é considerado o maior paisagista do século XX, tanto em nível nacional como mundial.

Pontual e Sá Carneiro (2005, p. 18) referem-se à inegável contribuição de Burle Marx para "a arquitetura paisagística brasileira como o inventor do jardim moderno, do jardim essencialmente brasileiro". Segundo Dourado (2009, p. 89), "Burle Marx tinha convicções claras sobre o papel que caberia ao paisagismo moderno, principalmente o potencial transformador na geração de melhores condições de vida pela criação de espaços verdes públicos". Para Sgard (1994, p. 72), o paisagista se empenhava na luta apaixonada em defesa da floresta brasileira. Em seus jardins, a espécie vegetal "não é utilizada como um simples material, nem mesmo apenas por sua cor, silhueta ou perfume, mas por sua personalidade própria".

Além da beleza do traçado, da criação de espaços adequados e da riqueza da composição vegetal encontrados em seus projetos, Burle Marx é reconhecido pela importância de ter introduzido e consolidado, em nossos jardins, o uso de espécies vegetais nativas do Brasil, numa época de grande dependência cultural, em que "a decoração floral dos jardins privados ou públicos só tem olhos para rosas, cravos e gladíolos importados da Europa" (LEENHARDT, 1994, p. 9). Burle Marx coloca essa ideia ao afirmar: "Utilizei o elemento nativo natural, com toda sua força e todas as suas qualidades, como uma matéria apta a concorrer para o meu projeto de composição plástica" (LEENHARDT, 1994, p. 67). O paisagista conceitua "jardim como sinônimo de adequação do meio ecológico para atender às exigências naturais da civilização" (TABACOW, 2004, p. 23).

Para Macedo (1999, p. 93), Burle Marx é "o arquiteto da modernidade, da ruptura, da conquista total da identidade nacional no projeto paisagístico, devida exclusivamente a uma forte identificação pessoal com a cultura modernista e com os valo- 
res culturais e ecológicos brasileiros". Nesse sentido, Delphin (2005, p. 23) afirma que, "a partir da década de 1930, a história do jardim brasileiro está vinculada às conquistas da arquitetura moderna e à obra de Burle Marx".

Em 1932, a convite de Lúcio Costa e Gregori Warchavchik, Burle Marx foi responsável pelo projeto do jardim da casa de Gregori Warchavchik, de novo estilo, em São Paulo. Em 1934, Burle Marx assumiu o cargo de diretor de Parques de Jardim em Recife, dando início a sua trajetória em reformas e elaboração de projetos públicos (FLEMING, 1996).

Burle Marx é o maior destaque no cenário brasileiro de paisagismo do século XX. Seus projetos se destacavam pela utilização de plantas nativas locais, e sua composição artística trabaIhava com a organização espacial dos elementos paisagísticos fundamentados pelos conceitos do estilo de arquitetura e artes plásticas modernistas. Para Tanure (2007), Roberto Burle Marx tinha a intenção de semear a "alma brasileira" através do uso de plantas da região.

Segundo Frota (2009, p. 137), sua atuação constante "no cenário artístico brasileiro e internacional fez dele um contemporâneo tão do agora, que muitas vezes se esquecia de que ele era um dos últimos grandes modernistas remanescentes da geração de Di Cavalcanti, Tarsila, Villa-Lobos, Portinari, Manuel Bandeira".

Na visão de Dourado (2009, p. 25), "nenhum outro paisagista do século XX teve seu trabalho tão associado à flora brasileira", devendo ser lembrado por sua "obstinação pelo conhecimento, valorização e defesa das plantas autóctones". Burle Marx associou seus conhecimentos em artes plásticas ao conhecimento das plantas, conseguido a partir de suas pesquisas realizadas em expedições à Amazônia e a outros ecossistemas, e estudos de diversas espécies vegetais tropicais. Para Oliveira (2009, p. 197), Burle Marx tinha como característica o "amplo conhecimento das correntes artísticas e paisagísticas internacionais, bem como um vasto repertório relativo aos costumes, tradições e apropriações locais da flora".

Além disso, Burle Marx buscava a valorização da flora nativa e a proteção da natureza, procurando despertar essa consciência em outros profissionais. Em palestra proferida em 1981, afirmou: "Se em nossas especificações de vegetação, nos projetos, procurarmos utilizar a flora autóctone, e o que é muito importante, se lutarmos para essa especificação ser concretizada, estaremos salvando muitas plantas do desaparecimento" (TABACOW, 2004, p. 164).

Na visão de Burle Marx, de acordo com Oliveira (2000, p. 3), existia relação entre a falta de conhecimento com a falta de apreço pelo patrimônio natural e "através da paisagem construída, poder-se-ia [...] trazer aos habitantes, o conhecimento das riquezas naturais do país e ao mesmo tempo ajudar a perpetuar espécies ameaçadas de extinção" (OLIVEIRA, 2000, p. 3).

Em seus projetos, o paisagista, segundo suas palavras, usava a vegetação como "elemento genuíno, da natureza, em toda sua força e qualidade, como matéria, organizada em termos e 
propósitos de uma composição plástica. Pelo menos é assim que entendo o paisagismo, como uma forma de manifestação artística" (MARX, 1987, p. 18).

Burle Marx soube inovar por meio da caracterização dos espaços livres pelas plantas tropicais inatas das regiões ("abrasileirando" os jardins e parques) em que projetava e pelo cuidado em integrar o projeto paisagístico à realidade do ecossistema, clima e cultura locais. O jogo de cores, volumes, contrastes e assimetrias eram pontos marcantes na estruturação visual de suas obras.

\section{Burle Marx em Teresina}

Em Teresina são encontrados três exemplos de projetos de Roberto Burle Marx: os jardins do Palácio do Karnak, sede do governo estadual, exemplo de espaço semipúblico; os jardins do Rio Poti Hotel, espaço privado; e a Praça Monumento Da Costa e Silva, exemplo de espaço público.

O escritório de Roberto Burle Marx (Burle Marx \& Cia. Ltda.) contava com a participação de paisagistas e arquitetos. O arquiteto Haruyoshi Ono participou dos três projetos realizados em Teresina, sendo, atualmente, o responsável pelo escritório de Roberto Burle Marx. Nos projetos dos jardins do Palácio do Karnak, datado de 1972, e da Praça Monumento Da Costa e Silva, de 1976, houve, ainda, a participação do arquiteto paisagista José Tabacow. No projeto dos jardins Rio Poti Hotel, de 1986, o paisagista Hugo Biagi Filho atuou colaborador. Enquanto que, na Praça Da Costa e Silva, o projeto arquitetônico do monumento ficou sob a responsabilidade do arquiteto Acácio Gil Borsoi (LOPES et al., 2013).

\section{Os jardins do Palácio Karnak}

Edificação muito conhecida dos teresinenses, o Palácio do Karnak é sede do governo do Estado do Piauí, tendo, segundo Bastos (1994, p. 335), iniciado sua história no último quartel do século XIX, quando era, então, uma chácara, tornando-se depois um colégio de ensino secundário. O prédio foi vendido, segundo Tito Filho (2002), nos primeiros anos da República, para uso residencial até 1926, quando foi vendido ao governador Mathyas Olimpio de Melo, que o tornou a sede do Poder Executivo.

O Palácio de Karnak e seu jardim estão inseridos em um conjunto urbano de grande valor histórico, arquitetônico e paisagístico para a cidade. Embora a construção seja de estilo neocolonial, Burle Marx desenvolveu um projeto moderno que não fugiu, em momento algum, à proposta que ele já vinha apresentando ao longo de seu trabalho como paisagista. Foi proposto um jardim funcional, em que se teria, claramente, a distinção entre os caminhos para carro, com revestimento de asfalto, e as áreas destinadas ao passeio de pedestres seriam revestidas com pedra de Piracuruca. Tratar-se-ia de um jardim com traçado moderno, com linhas simples, porém dinâmicas (FIG. 1).

Antes da reforma, existia uma fonte circular (FIG. 2), de desenho tradicional, em frente ao edifício, que foi aterrada. No 
mesmo local, Burle Marx colocou um espelho d'água, totalmente diferente do original, com características modernas, forma pura e assimétrica, atravessado por um passeio de placas de concreto, que pareciam flutuar sobre a água, recurso utilizado em outros projetos de sua autoria (FIG. 3).
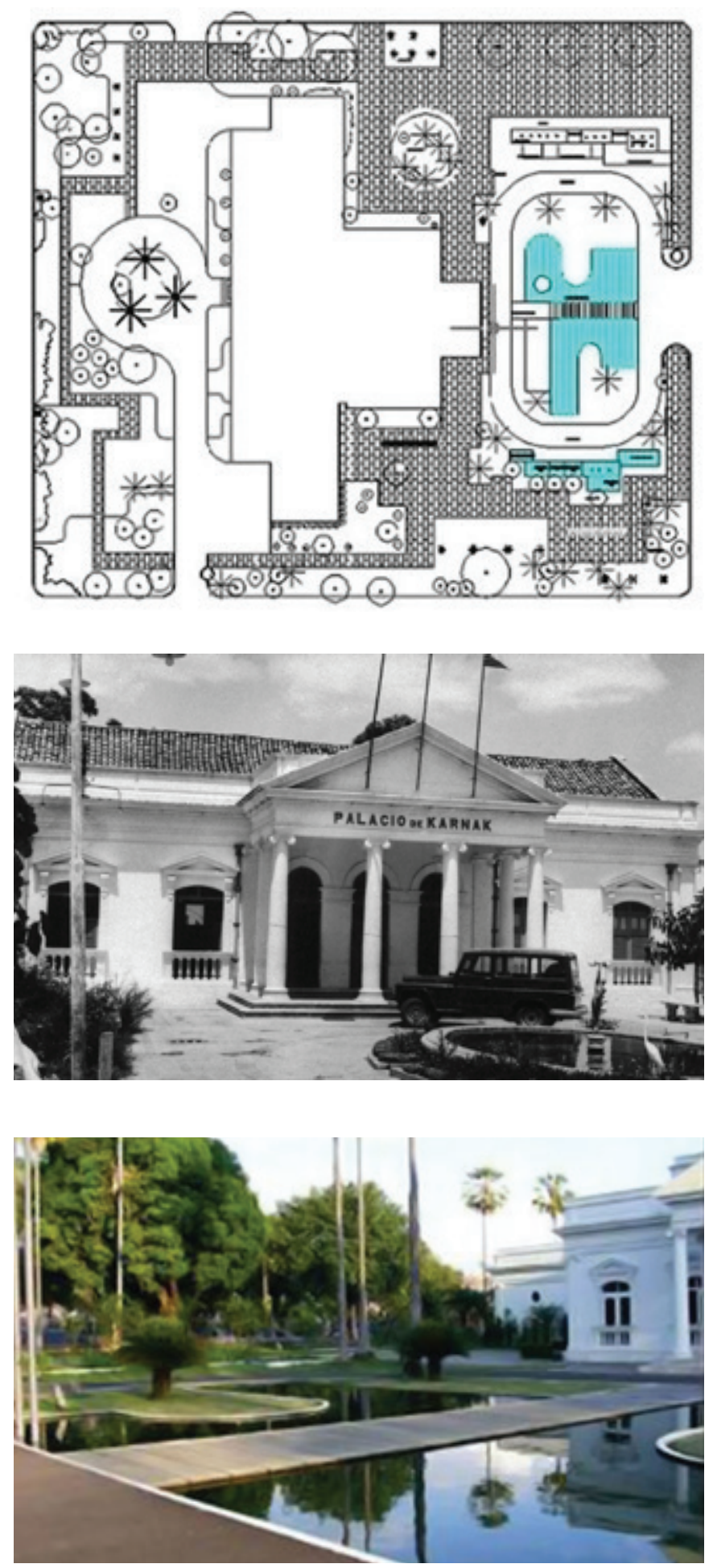

Figura 1 • Projeto dos jardins do Palácio de Karnak.

Fonte: Marx (1972), adaptado pelos autores.

Figura 2 • Jardim do Palácio de Karnak, antes da reforma.

Fonte: Arquivo Público (197-)

Figura $3 \bullet$ Jardim do Palácio de Karnak, após a reforma.

Fonte: Foto dos autores (2009).

Cadernos de Arquitetura e Urbanismo, v.21, n.29, $2^{0}$ sem. 2014 
No espaço em frente ao Palácio do Karnak, além do espelho d'água central, são encontrados mais dois, nas laterais do prédio, um do lado esquerdo (FIG. 4) e outro do lado direito (FIG. 5), para os quais foram indicadas espécies vegetais aquáticas.

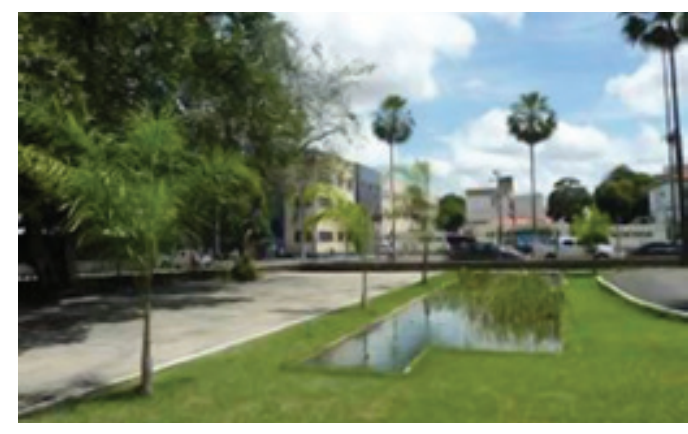

Foram aproveitadas 10 palmeiras carnaúbas e 18 árvores (oitis e caneleiros) já existentes no antigo jardim, que foram incorporadas ao novo traçado. Foram especificadas 58 espécies vegetais, sendo 12 espécies de herbáceas, espalhadas em diversos canteiros, 11 arbustos e 11 espécies aquáticas, de diferentes alturas, procurando criar um dinamismo, em contraposição à inércia da simetria neoclássica. Na parte posterior ao edifício, têm-se árvores de maior porte e dispostas próximas umas das outras. A diversidade de herbáceas e arbustos mostra a preocupação do paisagista com os planos e cores do projeto.

Segundo Leenhardt (1994), a introdução de diferentes tipos de plantas na paisagem tinha como objetivo torná-las parte do cotidiano das pessoas, aumentando seu conhecimento sobre flora. Para Burle Marx, o conceito de jardim era "como sinônimo de adequação do meio ecológico para atender às exigências naturais da civilização" (TABACOW, 2004, p. 23).

Nesse espaço, o traçado original se manteve, mas sem a vegetação especificada no projeto original. Cada nova gestão foi responsável pela remoção ou acréscimo de espécies vegetais, de acordo com a tendência da época e o gosto pessoal em cada administração.

Em pesquisa realizada, no primeiro semestre de 2010, foram encontradas apenas 12 espécies das indicadas no projeto original e, ainda, 28 espécies, distribuídas em 19 famílias, que não foram indicadas no projeto de Roberto Burle Marx. Dessa forma, a hierarquia das espécies vegetais inicialmente pensada no projeto original não mais existe, acarretando em jogos de planos e volumes pobres, o que resultou na perda de sua qualidade plástica.

\section{A Praça Monumento Da Costa e Silva}

A ideia para o projeto da Praça Monumento Da Costa e Silva surgiu em pleno "milagre econômico brasileiro", na década de 1970, ainda na ditadura militar, época de grandes construções no Estado do Piauí, beneficiado com o bom momento econômico do País. Nesse período, foram desenvolvidos diversos projetos para a cidade, capazes de mexer com a autoestima do povo. Segundo Santos e Kruel (2009), nesse período, foram
Figuras 4 e $5 \bullet$ Espelhos d'água do lado esquerdo e direito.

Fonte: Foto dos autores (2010). 
realizadas várias obras de grande porte, como a construção do Centro Administrativo, do Centro de Convenções, do Ginásio de Esportes Dirceu Arcoverde, o "Verdão", do Parque de Exposições Agropecuárias e do Hospital da Polícia Militar, além da abertura de grandes avenidas.

O governador do Piauí, Dirceu Arcoverde (1974-1978), convidou o arquiteto Acácio Gil Borsoi e o paisagista Roberto Burle Marx para criarem uma praça monumento, com a intenção homenagear Antônio Francisco da Costa e Silva, um dos mais famosos poetas do Piauí, autor do hino do Piauí, nascido em 1885, na cidade de Amarante, também banhada pelo rio Parnaíba. Foi sugerido o terreno existente ao longo da Avenida Maranhão que, situada às margens do Rio Parnaíba, acumulava água da lagoa existente no local, não a deixando escoar. Dessa forma, o então Secretário de Obras na época, Carlos Bulamarqui, propôs a construção de uma praça no local, para solucionar o problema.

O local não poderia ter sido melhor para a construção desse espaço, que tinha como objetivo ser um monumento e homenagear ao poeta que sempre ressaltava o rio Parnaíba em seus poemas. Na visão de Matos et al. (2007, p. 7), esse espaço não se tratava apenas de mais uma área livre, mas sim de "uma grandiosa referência cultural da cidade, uma homenagem às águas, representada pelas fontes, pelos espelhos d'água, pela cascata [...], que espelhavam a beleza, a leveza e a ternura dos poemas do poeta maior das águas do Parnaíba".

Segundo antigos moradores do bairro, antes da construção da praça, existiam no local algumas habitações populares e uma grande lagoa circundada por muito mato e capim, tendo sido necessária a execução de aterro para dar início às obras (FIG. 6). O entorno do terreno era constituído basicamente por residências (FIG. 7). Dessa forma, a criação do espaço público na área veio melhorar essa parte da cidade, sendo motivo de júbilo e de aceitação por parte da população do entorno.

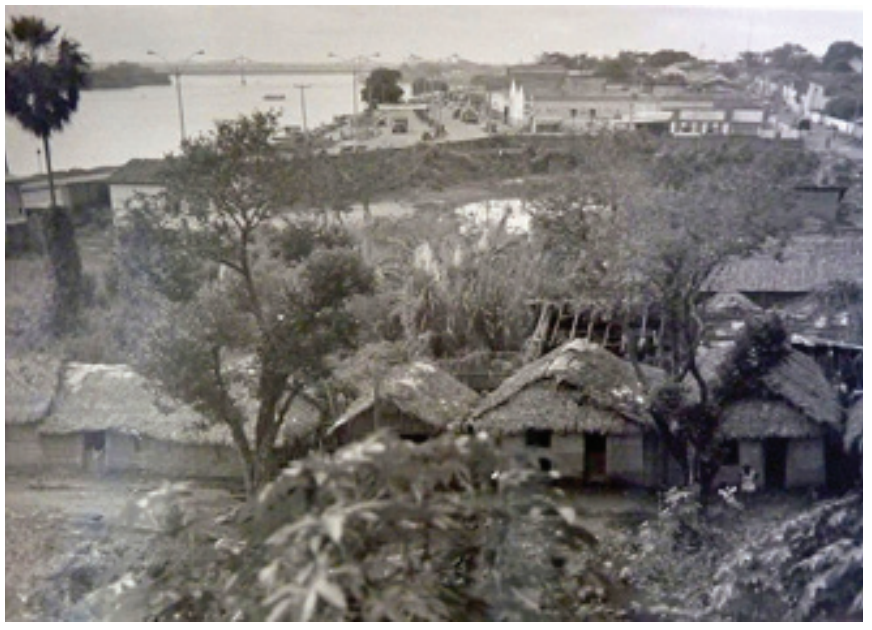

A praça está localizada no bairro Centro, entre as ruas João Cabral e Santa Luzia, e Avenidas José dos Santos e Silva e Maranhão, em terreno de forma trapezoidal. Trata-se de um
Figura $6 \bullet$ Vista do terreno antes da construção, vendo-se à esquerda o rio Parnaíba.

Fonte: Fonte: Acervo Escritório Burle Marx \& Cia. Ltda. (1975) 


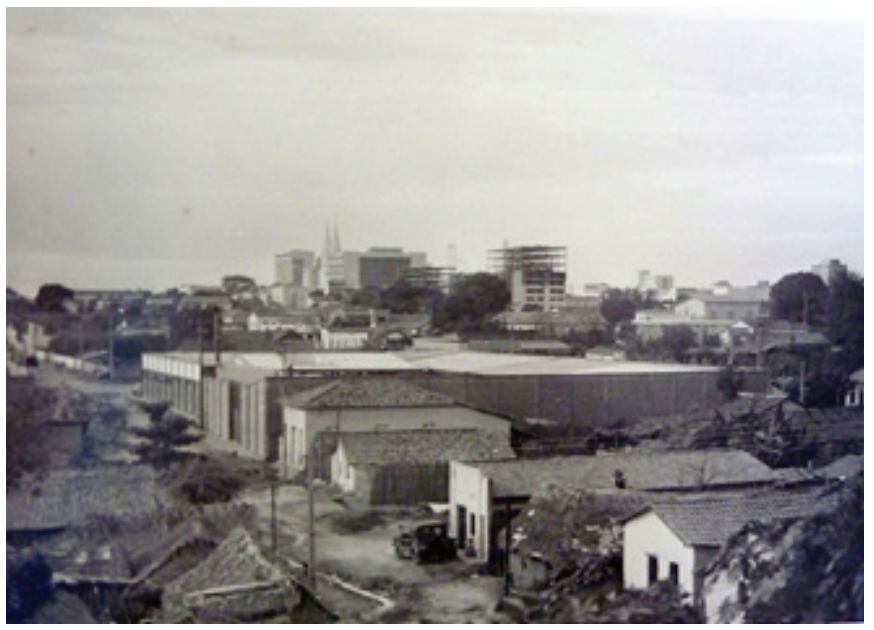

terreno com desnível, onde a parte mais alta corresponde à parte mais larga, na lateral sul, que foi aproveitada para implantação do monumento, com a cascata. O entorno do terreno era constituído basicamente por residências, destacando-se, ainda, na lateral sul, o Edifício da Cepisa e, no lado oeste, o rio Parnaíba, elemento bastante presente na paisagem.

Voltado para rio Parnaíba, o espaço foi projetado com extensas áreas de saibro, revestidas de grama ou pedra, propícias para circulação, brincadeiras das crianças e passeios de bicicleta. No projeto se destaca o grande círculo, no lado esquerdo da praça, que tem uma versão moderna do coreto tradicional, também circular, circundado por bancos e o grande espelho d'água no centro da praça. No projeto original, os bancos foram agrupados em quatro locais da praça, três deles estão localizados na calçada voltada para o rio e sombreados por grupos de árvores.
Figura $7 \bullet$ Vista do entorno da Praça Da Costa e Silva, em 1975

Fonte: Fonte: Acervo Escritório Burle Marx \& Cia. Ltda. (1975)

Figura 8 • Planta da Praça Da Costa e Silva Fonte: Marx (1976), adaptada pelos autores (2009).

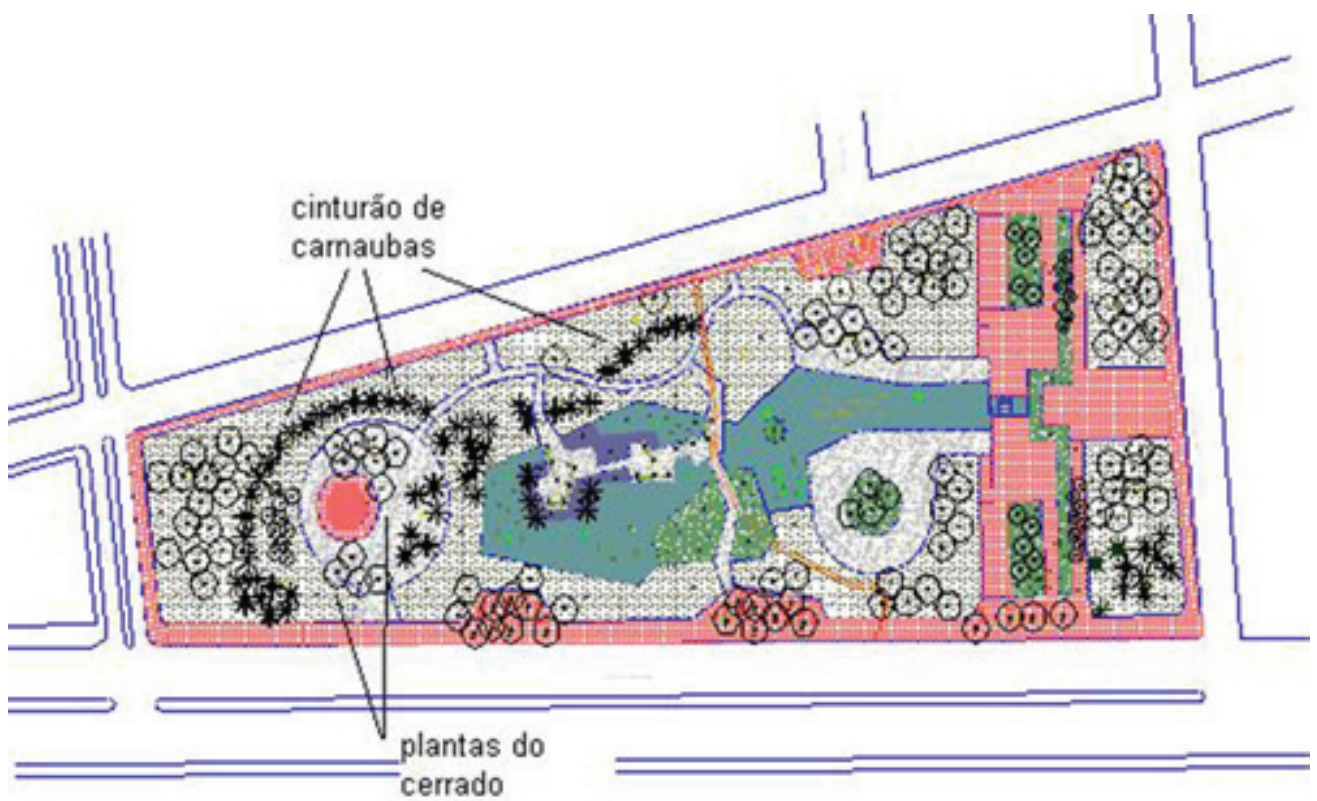




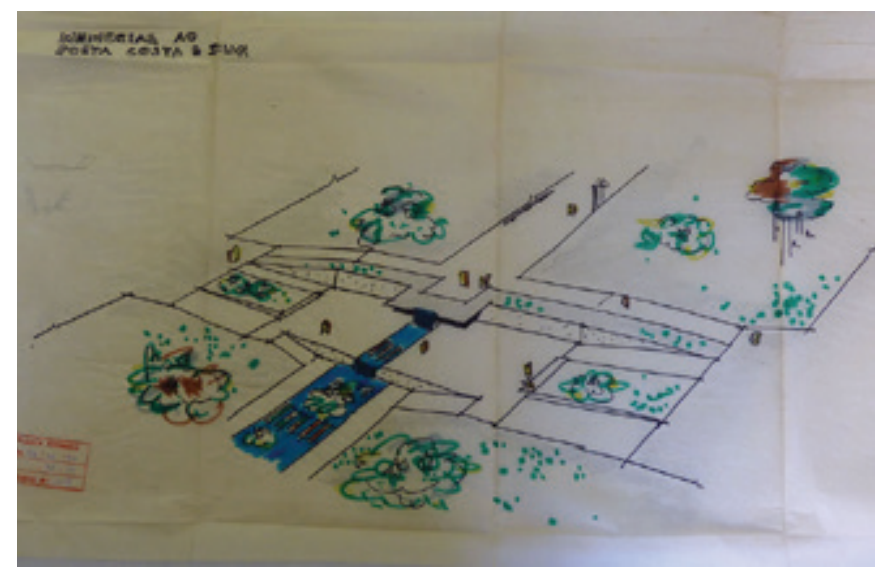

A praça tem uma parte mais elevada, do lado direito, que foi aproveitado para a implantação da cascata, que forma o espeIho d'água, de linhas retas e irregulares. Por meio de passeios, caminhava-se sobre ele, onde também estavam inseridas estruturas de ferro com a função de apoio para trepadeiras.

O memorial em homenagem ao poeta foi idealizado pelo arquiteto Acácio Gil Borsoi, composto de estrutura de concreto aparente, em balanço, por onde corria a água que alimentava o espelho d'água, formado por linhas retas e irregulares, conforme croqui do arquiteto, datado de junho de 1975 (FIG. 9).

Abaixo da marquise, foi colocada uma placa de concreto no piso, contendo resumo da biografia de Da Costa e Silva e painéis de acrílico nas paredes, com trechos de suas poesias. Nos painéis estavam gravados trechos de seus poemas, como "Madrigal de um louco," "Saudade," "A queimada", "A enchente", "A derrubada", "A moenda", "Amarante", "A cantiga", "A balsa", "O aboio", "Elêusis" e "Sob outros céus" (DEZ..., 1977). Em 1993, para combater a ação de vândalos, que danificavam as placas de acrílico, foi feita a substituição por placas de aço escovado, mas que também foram roubadas, restando hoje no local apenas a placa de concreto.

Em foto de 1978, logo após a inauguração, é possível observar o uso da praça pela população. No primeiro plano observa-se a formação das palmeiras e o coreto e, ao fundo, os jatos d'água em funcionamento (FIG. 10). Nesse período, a praça era bem movimentada, sendo aproveitada por muitas pessoas, que se divertiam com as diversas atividades que lá ocorriam.

Segundo moradores mais antigos do entorno, no local, havia uma feirinha que atendia os banhistas, que aproveitavam a proximidade do rio para se divertirem. Com venda de comida e pequenos objetos, a feirinha tornava-se um atrativo durante os fins de semana. Ocorriam também festas relacionadas a datas comemorativas, como Dia da Criança e Dia da Cultura, que, com o passar dos anos, foram transferidas para outros pontos da cidade.

Segundo Silva (2005, p. 182), em seus projetos, Burle Marx buscava "criar em cada jardim um motivo diferente relacionado à paisagem", seguindo três princípios básicos em suas
Figura 9 • Croqui de Acácio Borsoi do Memorial Da Costa e Silva 


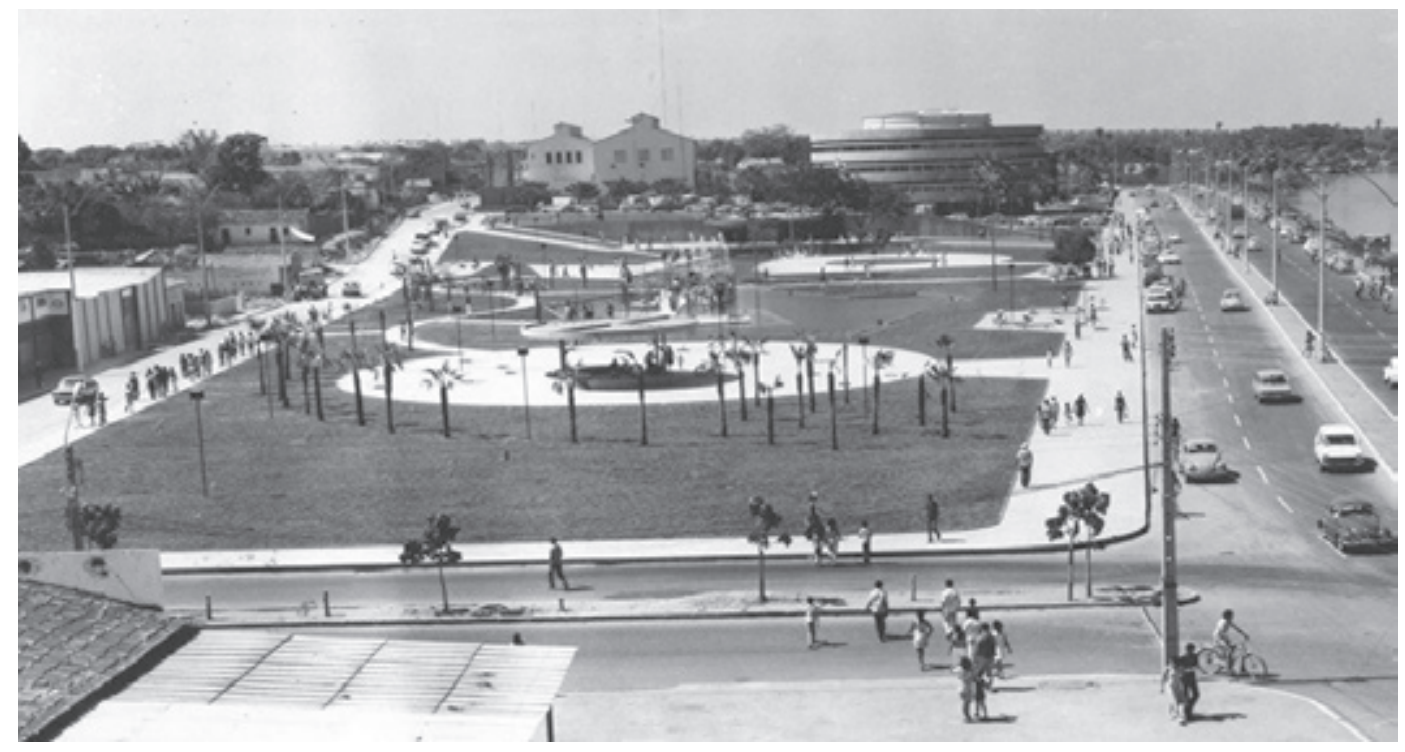

obras: a relação com o entorno, a hierarquia de caminhos e a presença de pontos focais. Nesse projeto, percebe-se a presença desses princípios quando o paisagista aproveita o desnível do terreno para a implantação da cascata que desce pequena sobre o monumento e cresce no horizonte, uma referência ao rio Parnaíba. A hierarquia se faz presente, pois os caminhos são mais largos quanto mais próximos do coreto e do lago artificial, são esses dois pontos focais em lados opostos, não existindo, portanto, a intenção de concentrar os usuários em apenas um local.

A intenção no projeto era possibilitar a interação e integração entre a praça e o rio. Nos dias atuais, já não existe integração nem mesmo a valorização visual do rio Parnaíba, pois o gradil existente no local e a Ponte José Sarney, construída em 2002, podem ser considerados barreiras visuais.

O entorno da praça, inicialmente composto de residências, tornou-se basicamente comercial, com predomínio de lojas de venda a atacado, que não envolvem grande movimentação de pessoas. Além disso, a sociedade se modificou e foi perdido o costume da vivência nas calçadas. Dessa forma, as ruas próximas passam a maior parte do tempo vazias, favorecendo a presença de marginais, o que tornam o lugar inseguro.

Não há por parte dos moradores da região uma apropriação do espaço, propiciando o esvaziamento da área na maior parte do dia, tornando o lugar propício para marginais. Observa-se que o ambiente urbano criado pelas atividades no entorno da Praça Monumento não propicia usuários suficientes para que o local possa exercer, plenamente, sua função de espaço público, estabelecendo relações sociais e vínculos.

No projeto foram indicadas 34 espécies, sendo 11 árvores, 5 arbustos, 9 espécies aquáticas, 2 tipos de herbácea para forração, 1 gramínea e 3 espécies de trepadeiras. Além disso, foram previstos três tipos de palmeiras colocadas em fileiras, em grupos ou ainda em canteiros aquáticos. Atualmente, há
Figura $10 \bullet$ Vista geral da Praça Da Costa e Silva, pouco tempo após a inauguração 
apenas seis espécies das especificadas inicialmente, acrescidas de 17 espécies, que não foram especificadas no projeto de Burle Marx.

O traçado original do projeto não foi muito modificado, permanecendo quase o mesmo, sendo apenas acrescidos caminhos, com piso de concreto. O espelho d'água encontra-se desativado (FIG. 11), o local do monumento está completamente pichado, e as placas dos poemas foram roubadas, somente restando a placa de concreto.

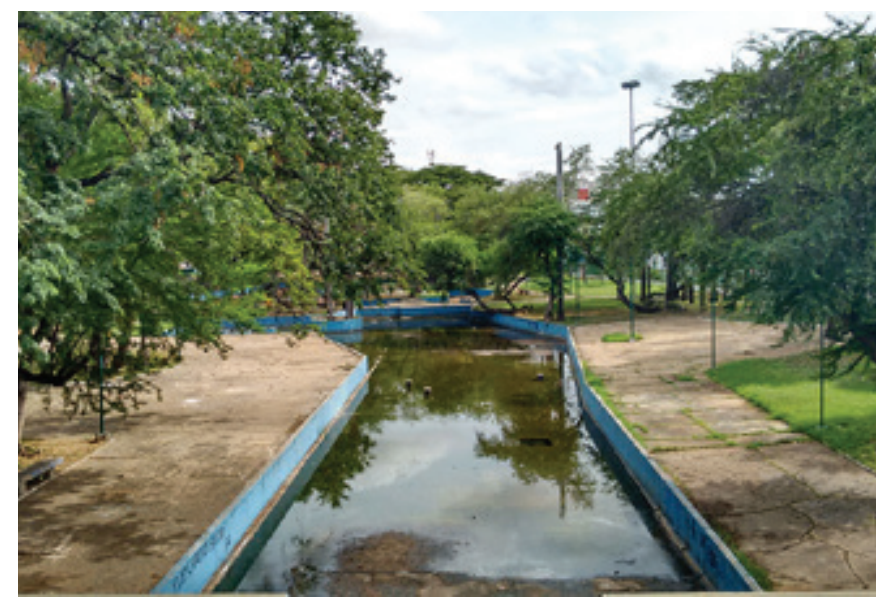

Quem conheceu o local com as fontes e o espelho d'água em pleno funcionamento sempre destaca a beleza desses equipamentos e da praça como um todo. O local servia de cenário para fotos dos moradores do entorno e de usuários, registrando momentos da vida dos habitantes da cidade.

As praças são locais de convívio, circulação e permanência de pessoas. Saldanha (1986, p. 17) diz que a praça "significa no fundo a consolidação da vida pública", são elementos de importância estrutural para o espaço urbano, pois funcionam como conectivos entre pessoas, atividades e lugares.

\subsection{Os jardins do Rio Poty Hotel}

O Hotel Rio Poty foi construído em 1983 e inaugurado em dezembro de 1987, projetado pelo arquiteto Ricardo Roque. Na arquitetura do edifício, evidenciam-se a horizontalidade e o uso de concreto armado.

A iniciativa de procurar Burle Marx para o projeto paisagístico do hotel partiu do arquiteto, já que a ideia era criar um atrativo turístico, incentivando o turismo de negócios na cidade. O contato com o escritório de Burle Marx se deu por meio de Acácio Gil Borsoi e Janete Costa, arquitetos atuantes em Recife e no Rio de Janeiro, onde ficava o escritório do paisagista.

No projeto do jardim do hotel, datado de 1986, foram usadas linhas retas e sinuosas, no qual se destaca, na parte interna, o espaço circular do caramanchão com sua fonte, o traçado irregular da piscina, interligados por passeios e caminhos irregulares de pedra, envolvidos por densa vegetação, trazendo a natureza para o espaço construído (FIG. 12).
Figura 11 • Espelho d'água desativado

Cadernos de Arquitetura e Urbanismo, v.21, n.29, $2^{0}$ sem. 2014 


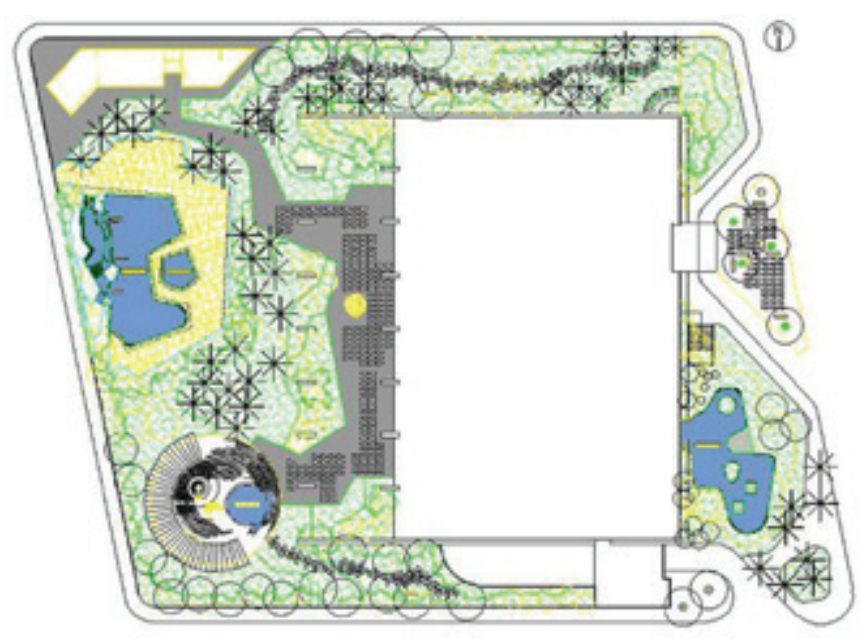

A piscina está em bom estado de conservação, e as espécies especificadas próximas a ela no projeto original também não sofreram alterações quanto à situação atual. A área onde estão os coqueiros e carnaúbas mantém o mesmo traçado do projeto original, mas perdeu algumas de suas espécies (um coqueiro e quatro carnaúbas). A carnaúba (Copernicia cerifera) aparece em destaque no jardim (FIG. 13).

$\mathrm{Na}$ área sul do jardim, foi criado de um passeio com blocos retangulares de concreto, ligando piso coberto com canteiro lateral. Também foi criado outro passeio utilizando blocos retangulares de concreto interligando a área do caramanchão e a piscina (FIG. 14). Nas laterais do terreno do hotel, conservaram-se as espécies e houve poucas alterações nas quantidades de vegetais.
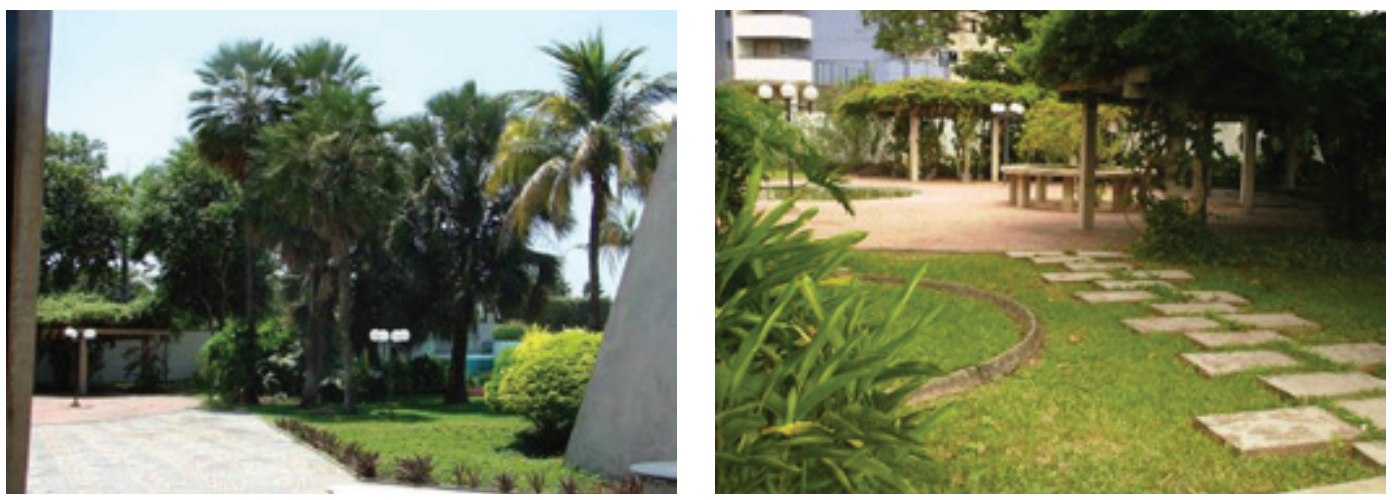

Devido aos custos decorrentes da execução e posterior manutenção, o projeto sofreu algumas alterações ao longo do tempo: espécies que não se adaptaram ao clima e acabaram morrendo, outras que foram substituídas no decorrer dos anos, os sistemas de água que são desativados pelo custo acarretado por sua manutenção. Entretanto o traçado mantém correspondência com os planos de Burle Marx.

Nos jardins do Rio Poty, Burle Marx usou os elementos da paisagem local para compor seus espaços, tornando-os únicos.
Figura 12 • Jardim do Rio Poty Hotel. Fonte: Marx (1986), adaptado pelos autores (2010)
Figuras 13 e 14 - Palmeira carnaúba em trecho do jardim. Vista do passeio criado ligando caramanchão à piscina.

Foto dos autores (2009). 
O Rio Poty Hotel abriga o único exemplo de espaço privado projetado por Burle Marx em Teresina, o que faz com que ele se mantenha em bom estado através do tempo, apesar das modificações decorrentes do alto custo da manutenção e das agressões sofridas por parte dos usuários.

Segundo Andrade (2008, p. 138), a preservação dos jardins históricos, ou jardins de interesse histórico, justifica-se por sua "sua significação cultural, que contribui para o fortalecimento da memória e da identidade de uma sociedade, bem como na leitura e na qualificação da cidade".

Sá Carneiro (2009b, p. 55) afirma que os jardins projetados por Burle Marx nas cidades do Nordeste foram criados tendo por base os elementos da paisagem cultural de cada cidade. Observa-se que as características da paisagem "dos jardins expressavam o tipo de vegetação local, da planta como elemento da concepção, de modo que as pessoas, os habitantes urbanos, enfim, se identificassem com a paisagem e vice-versa, ou seja, o jardim desempenhasse uma função memorial."

\section{Considerações finais}

A Praça Monumento Da Costa e Silva reúne três aspectos importantes relacionados ao patrimônio cultural da cidade de Teresina, representados pela ligação do espaço com o rio Parnaíba, a representatividade da praça como monumento ao poeta mais importante do Estado e por ser único exemplo de espaço público existente na cidade, projetado por Roberto Burle Marx, maior paisagista brasileiro, renomado internacionalmente. Dessa forma, por se tratar de um espaço público que acumula histórias e significados, fazendo parte da identidade e patrimônio cultural da cidade, é importante que seja preservado, revitalizado e resguardado para a posteridade. Não menos importantes são os jardins do Palácio de Karnak e do Rio Poty Hotel, pelas características de seus projetos, que apresentam conceitos desenvolvidos por Burle Marx, de grande valor histórico, arquitetônico e paisagístico para a cidade.

Burle Marx consolidou a identidade paisagística brasileira com o uso de vegetação local, análise do clima do entorno de suas obras e, ainda, por aliar seus conhecimentos em artes plásticas à produção dos desenhos de pisos e composições vegetais. Devido à importância da preservação da paisagem cultural para a sociedade local, faz-se necessário que sejam realizadas ações no sentido de preservar tais ambientes para que não sejam descaracterizados e torná-los patrimônios histórico-culturais para uso da população atual e de futuras gerações.

\section{Referências}

ANDRADE, Inês El-Jaick. Construção e desconstrução do conceito de jardim histórico. Risco. São Carlos, v.8, p. 138-144, 2008.

ANDRADE, Inês El-Jack; MARTINS, Rosina Trevisan. Um olhar sobre os jardins: a preservação dos jardins históricos. In: ENCONTRO NACIONAL DO ENSINO DE PAISAGISMO EM ESCO-

Cadernos de Arquitetura e Urbanismo, v.21, n..29, 20 sem. 2014 
BARTALINI, Vladimir. Sintonias e defasagens: os parques públicos nos planos para São Paulo. Paisagem e ambiente: ensaios. São Paulo: FAU, n. 7, p. 69-89, 1995.

BASTOS, Cláudio de Albuquerque. Dicionário e geográfico do Estado do Piauí. Teresina: Fundação Cultural Monsenhor Chaves, 1994.

CARNEIRO, Henrique. Banalização do patrimônio cultural material e consequências perversas para a vida na cidade. In: MARTINS, Clerton (Org.). Patrimônio Cultural: da memória ao sentido do Lugar. São Paulo: Roca, 2006, p. 17-30.

COSTA, Lucia Maria; MONTEIRO, Patrícia Maya. Rios urbanos e valores ambientais. In: DEL RIO, Vicente; DUARTE, Cristiane Rose; RHEINGANTZ, Paulo Afonso (orgs.). Projeto do lugar: colaboração entre Psicologia, Arquitetura e Urbanismo. Rio de Janeiro: Contra Capa Livraria; Proarq, 2002, p. 291-298.

CURY, Isabelle (Org.). Cartas patrimoniais. 2. ed. Rio de Janeiro: IPHAN, 2000.

DELPHIN, Carlos Fernando de Moura. Manual de intervenções em jardins históricos. Brasília: IPHAN, 2005.

DEZ mil pessoas na inauguração da praça. O Estado, Teresina, 6 set. 1977.

DOURADO, Guilherme Mazza. Modernidade verde: jardins de Burle Marx. São Paulo: Senac São Paulo, 2009.

FLEMING, L. Roberto Burle Marx: um retrato. Rio de Janeiro: Index, 1996.

FRONER, Yacy Ara. Patrimônio histórico e modernidade: construção do conceito a partir da noção de revitalização de sítios, monumentos e centros urbanos. In: SIMPÓSIO DE TÉCNICAS AVANÇADAS EM CONSERVAÇÃO DE BENS CULTURAIS 1, 2002, Olinda. Anais... Olinda: Prefeitura Municipal de Olinda, 2002.

FROTA, Lélia Coelho. Roberto Burle Marx, um modernista planetário. In: CAVALCANTI, Lauro; EI-DAHDAH, Farés. Roberto Burle Marx, a permanência do instável: 100 anos. Rio de Janeiro: Rocco, 2009, p. 133-151.

ICOMOS. Jardins históricos: Carta de Florença. 1982. Disponível em: <http://5cidade.files.wordpress.com/2008/03/carta-de-florenca.pdf>. Acesso em: 17 jul. 2014.

Leenhardt, Jacques. Paisagem, Botânica e Ecologia. In: LEENHARDT, Jacques (Org.). Nos jardins de Burle Marx. São Paulo: Perspectiva, 1994, p. 47-67.

LEITÃO, Lúcia (org.). As praças que a gente tem, as praças que a gente quer: manual de procedimentos para intervenção em praças. Recife: Secretaria de Planejamento, Urbanismo e Meio Ambiente, 2002.

LIMA, Jorge da Cunha. Cultura pública: a organização política do sonho. São Paulo: Senac, 2002.

LOPES, Wilza Gomes Reis; MATOS, Karenina Cardoso; LEAL 
JR., J. H. L.; BARROS, R. F. M. Burle Marx em Teresina: a Praça Monumento da Costa e Silva. In: SÁ CARNEIRO, A. R.; SILVA, A. F.; SILVA, J. M. (Org.). Jardins de Burle Marx no Nordeste do Brasil. Recife: Ed. Universitária da UFPE, 2013.

LOPES, Wilza Gomes Reis; MATOS, Karenina Cardoso; MIRANDA, Alexsandra Ferreira Gomes; BARROS, Cézar Marco Correia. Um jardim de Burle Marx em Teresina: resgatando o projeto original. In: PAISAGEM NA HISTÓRIA: JARDINS E BURLE MARX NO NORTE E NORDESTE, 5, 2007, Recife. Anais... Recife: UFPE, 2007.

MACEDO, Silvio Soares. Quadro de paisagismo no Brasil. São Paulo: FAU/USP, 1999.

MARTINS, Clerton. Patrimônio cultural e identidade: significado cultural e sentido do lugar turístico. In: MARTINS, Clerton (org.). Patrimônio cultural: da memória ao sentido do lugar. São Paulo: Roca, 2006, p. 39-50.

MARX, Roberto Burle. Arte e paisagem: conferências escolhidas. São Paulo. Nobel, 1987.

MARX, Roberto Burle. Burle Marx \& Cia Ltda. Hotel Rio Poty. Teresina - Piauí. Rio de Janeiro, agosto de 1986. Plantas diversas. Cópias heliográficas.

MARX, Roberto Burle. Burle Marx \& Cia Ltda. Palácio de Karnak. Teresina - Piauí. Rio de Janeiro, junho de 1972. Plantas diversas. Cópias heliográficas.

MARX, Roberto Burle. Burle Marx \& Cia Ltda. Praça Da Costa e Silva. Teresina - Piauí. Rio de Janeiro, abril de 1976. Plantas diversas. Cópias heliográficas.

MATOS, Karenina Cardoso; LOPES, Wilza Gomes Reis; MATOS, Indira Cardoso; FREITAS, Samir Antonio Melo; BARROS, Cézar Marco Correia. O rio como atrativo cultural na paisagem urbana de Teresina. In: PAISAGEM NA HISTÓRIA: JARDINS E BURLE MARX NO NORTE E NORDESTE, 5, 2007, Recife. Anais... Recife: UFPE, 2007.

MOTTA, Flávio Lichtenfels. Roberto Burle Marx e a nova visão da paisagem. São Paulo: Nobel, 1983.

MURTA, Stela Maris; GOODEY, Brian. Interpretação do patrimônio para visitantes: um quadro conceitual. In: MURTA, Stela Maris, ALBANO, Celina (Org.). Interpretar o patrimônio: um exercício do olhar. Belo Horizonte: Ed. UFMG; Território Brasilis, 2002.

NUNES, Maria Cecília Silva de Almeida. A invenção de Teresina em uma perspectiva lendária. In: VASCONCELOS, José Geraldo; ADAD, Shara Jane Holanda Costa (orgs.). Coisas de cidade. Fortaleza: Editora UFC, 2005.

OLIVEIRA, Ana Rosa de. "Obsessionário Burlemarxiano": apresentação de algumas constantes do método de Roberto Burle Marx. In: ENCONTRO NACIONAL DE PAISAGISMO EM ESCOLAS DE ARQUITETURA E URBANISMO NO BRASIL, 5, 2000, Rio de Janeiro. Anais... São Paulo: Semiotic, 2000. [1 CD-ROM.] OLIVEIRA, Fabiano L. O lugar do jardim: debates sobre a criação de uma paisagem moderna e brasileira. In: SÁ CARNEIRO, Ana Rita; BERTRUY, Ramona, Pérez (orgs.). Jardins históri- 
cos brasileiros e mexicanos. Recife: Editora Universitária da UFPE, 2009, p. 175-210.

PELEGRINI, Sandra C. A. Cultura e natureza: os desafios das práticas preservacionistas na esfera do patrimônio cultural e ambiental. Revista Brasileira de História. São Paulo, v. 26, n. 51, p. 115-140, 2006.

PONTUAL, Virgínia; SÁ CARNEIRO, Ana Rita. Introdução. In: PONTUAL, Virgínia; SÁ CARNEIRO, Ana Rita (orgs.). História e Paisagem: ensaios urbanísticos do Recife e de São Luís. Recife: Bagaço, 2005.

SÁ CARNEIRO, Ana Rita. A restauração do Jardim das Cactáceas de Burle Marx no Recife, Brasil. In: SÁ CARNEIRO, Ana Rita; BERTRUY, Ramoona, Pérez (orgs.). Jardins históricos brasileiros e mexicanos. Recife: Editora Universitária da UFPE, 2009a, p. 211-239.

SÁ CARNEIRO, Ana Rita. Atuação de Burle Marx na construção da paisagem através de projetos paisagísticos no Nordeste do Brasil. Leituras paisagísticas: teoria e práxis. Rio de Janeiro: EBA Publicações; UFRJ, 2009b, n. 3, p. 38-61.

SÁ CARNEIRO, A. R.; SILVA, Aline Figueirôa; GIRÃO, Pricilla Amorim. O jardim moderno de Burle Marx: um patrimônio na paisagem do Recife. In: SEMINÁRIO NACIONAL DOCOMOMO, 5, 2003, São Carlos. Anais... São Carlos: EESC, 2003.

SALDANHA, N. O jardim e a praça, ensaio sobre o lado privado e o lado público da vida social e histórica. Porto Alegre: Sergio Antonio Fabris Editor, 1986.

SANTOS, Gervásio; KRUEL, Kenard. História do Piauí. Teresina: Halley, 2009.

SERPA, Ângelo. Os espaços livres de edificação nas periferias urbanas um diagnóstico preliminar em São Paulo e Salvador. Paisagem e ambiente: ensaios, São Paulo, n. 10, p. 189-216, dez. 1997.

SILVA, Aline. Os princípios artísticos do traçado dos jardins de Burle Marx no Recife. In: PONTUAL, Virginia; SÁ CARNEIRO, Ana Rita (org.) História e Paisagem: ensaios urbanísticos do Recife e de São Luís. Recife: Bagaço, 2005.p.175-202.

SGARD, Jacques. Burle Marx e a estética da paisagem. In: LEENHARDT, Jacques (org.). Nos jardins de Burle Marx. São Paulo: Perspectiva, 1994, p. 69-73.

TABACOW, José. Roberto Burle Marx: arte \& paisagem (conferências escolhidas). 2. ed. São Paulo: Studio Nobel, 2004.

TANURE, Joana Dias. O projeto de paisagismo de Burle Marx e equipe para o "Parque da cidade" em Brasília/DF. 2007. 218f. Dissertação (Mestrado em Arquitetura e Urbanismo) - Faculdade de Arquitetura e Urbanismo, Universidade de Brasília, Brasília.

TITO FILHO, A. Teresina meu amor. 4. ed. Teresina: Comepi, 2002.

VIEIRA, Maria Elena Merege. O jardim e a paisagem: espaço, arte, lugar. São Paulo: 2007. 